\title{
The Effect of Social-Emotional Competence on Children Academic Achievement and Behavioral Development
}

\author{
Mona Alzahrani ${ }^{1}$, Manal Alharbi ${ }^{1} \&$ Amani Alodwani ${ }^{1}$ \\ ${ }^{1}$ University of South Florida, USA \\ Correspondence: Amani Alodwani, University of South Florida, USA.
}

Received: July 30, 2019

doi:10.5539/ies.v12n12p141
Accepted: September 15, $2019 \quad$ Online Published: November 29, 2019

URL: https://doi.org/10.5539/ies.v12n12p141

\begin{abstract}
In this paper, we explore the importance of the social-emotional competence on children's growth. To develop children social-emotional competence, an interaction between adults and children is critically needed. Teachers have the responsibility to enhance children's development in many aspects, including social, emotional, cognitive, academic, and behavioral skills. A positive relationship between teachers and young students helps those students to have better school achievement and behavioral skills. We review several studies that show the influence that social and emotional competence has on children's learning outcomes and on their ability to engage in good behaviors. We also provide several strategies that help teachers to build strong and healthy relationships with children. These strategies foster children's academic and behavioral success. We define social and emotional learning in relation to school successes to show that competence in these areas increases students' reading, writing, critical thinking, and vocabulary skills. Emotional regulations can also enhance school achievement, both in the present and in the future. Additionally, we provide strategies that teachers can use to foster positive behavioral skills.
\end{abstract}

Keywords: social-emotional competence, teacher-child relationship, behavioural skills, academic achievement, young children

\section{Introduction}

Take a moment to think about a teacher who had an impact on your life. For most children, their positive or negative educational experiences affect their development. These experiences affect children's academic development, behavior, and social and emotional competence. Thus, in-depth examinations of the teacher-child relationship are essential. In addition, ensuring that these relationships are healthy and strong will help children to develop social-emotional, academic, and behavioral skills .

Young children are very sensitive, so most teachers try to help them to build important social skills. The teacher-child relationship must be examined in depth because many researchers have found strong links between these relationships and the children's behavior and academic success (Lippard, Paro, Rouse, \& Crosby, 2018). Particularly in preschool and kindergarten, this relationship has a big impact on children's development; this impact lasts well into primary school (Lippard et al., 2018). Lippard et al. (2018) also found that strong teacher-child relationships help children to develop good behavioral skills and school success, cognitive, social, and emotional skills.

To ensure that children are healthy, adults must support the development of their social and emotional skills, which are of great importance to the children's education as well. Social and emotional skills also help children to live healthy and safe lives. Children must develop many skills in their early years, including the ability to do the following: communicate with adults, interact with peers in the classroom, form relationships with others, express emotions, self-regulate, show empathy, be motivated, and engage socially. Children need a long time to develop these skills, so teachers must develop children's social and emotional competence every day through the use of various activities. A good-healthy relationship between the teacher and the child is also needed in the development of a healthy social-emotional competence. Hence, this paper is meant to show the impact that social and emotional competence has on children's academic achievement and behavioral skills).

\subsection{Social and Emotional Development}

Social and emotional developments are important to growth in early childhood. These social and emotional skills 
are associated with the ability to communicate with others in the classroom (e.g., teachers and peers) and outside of school. Social and emotional skills influence how children interact with others, how they deal with their emotions, and how they react to the events that happen around them.

In addition, these social and emotional skills are correlated with the ability to properly express emotions such as happiness, sadness, nervousness, and anger; these skills also help children determine how to act when they feeling one of these emotions. In addition, children can learn about their own feelings and identities by practicing social and emotional skills with their peers and teachers. Wu, Hu, Fan, Zhang, and Zhang (2018) defined social and emotional competence as the use of acceptable behavior to socialize with others and to foster positive interaction.

Many teachers are keen to regularly support their students' development of social and emotional skills. Lippard et al. (2018) argued that children are more likely to engage in positive behavior and less likely to misbehave when they grow in class as a result of support from teachers. Lippard et al. (2018) also revealed that, when teachers focus on support, they increase children's positive outcomes and help them to develop cognitive skills. Similarly, Breeman et al. (2015) indicated that positive teacher-child relationships improve children's psychosocial abilities and their motivation to communicate in the classroom.

On the other hand, negative teacher-child relationships affect children's behavior and cause them to dislike interacting with their peers in the classroom (Breeman et al., 2015). Breeman et al. (2015) stated that negative communication between peers impacts children's emotional, social, and behavioral skills.

Lippard et al. (2018) mentioned that many scholars have shown the teacher-child relationship to affect all children in the classroom equally. However, Lippard et al. (2018) also argued that children can have different experiences when interacting with the same teacher in the same classroom. Nevertheless, Cadima, Verschueren, Lea, and Guedes (2016) found that, among young children, there is no association between self-regulation and the teacher-child relationship. Cadima et al. (2016) also found that children have individual classroom experiences because each student has a distinct relationship with the teacher.

Sutherland et al. (2018) said that children with problematic behaviors are likely to experience developmental difficulties, both in childhood and in adulthood. Furthermore, Sutherland et al. predicted that behavioral problems at a young age are strongly linked to behavioral challenges in adolescence (e.g., drug use, violence, and dropping out of school). Sutherland et al. noted that interventions (such as classroom activities) are very important when seeking to modify children's behavior in early childhood. Sutherland et al. also found that children who lack social skills, behavioral competence, or emotional skills are at a disadvantage in the classroom.

Consequently, young children need more support than older children. In addition, efforts to raise a healthy adolescent or adult must start in early childhood. Thus, preschool and kindergarten are fundament to children's development, as they ensure that children have a good foundation of social, emotional, and behavioral skills. Early-childhood teacher are responsible for supporting children and developing their social, emotional, and cognitive competence; thus, teachers must understand their students' characteristics and use various activities to help them become healthy adolescents. Ng and Bull (2018) noted that excellent teachers facilitate social and emotional learning using small-group activities. Interacting with children in one-on-one activities also supports their development (Ng \& Bull, 2018).

\subsection{Teacher-Child Relationships}

Preschool and kindergarten teachers play an important role in developing young children's skills. These teachers must have specific characteristics, such as honesty, patience, flexibility, fairness, and respect for all children. Graves and Howes (2011) declared that teachers' perceptions have a big impact on how they deal with students. Breeman et al. (2015) illustrated that teachers with high levels of well-being have a strong influence on their students' social and emotional development.

Teacher-child relationships are important part to the education process. A positive relationship is necessary to support children's development. Children personally enjoy interacting with teachers who are kind, patient, flexible, creative, and dedicated. The majority of children interacts with and listens to teachers whom they feel comfortable with. Early-childhood teachers thus need to have high-quality education. Thus, parents always look for the best and kindest teachers for their children, particularly young children.

Teachers have many opportunities to build strong relationships with their students. Moreover, teachers can develop relationships with students through the use of various strategies and activities. Making a difference in young children's lives is a great part of this job, and every teacher should take the opportunity to develop children's social and emotional skills, thus changing their behaviors and ensuring their success in life. The dynamic of the teacher-child relationship has a massive effect on children's school lives. White (2015) mentioned that a good 
teacher-child relationship has many benefits for young children and that these benefits continue for a long time afterward.

Children need to feel safe and comfortable with their teachers. Thus, teachers can build a strong relationship with their students over time by showing respect, listening to them, talking to them, and making eye contact with them during everyday communication. White (2015) stated that preschool and kindergarten students who have healthy teacher-child relationships, as compared to those who do not, exhibit better peer communication in the classroom and have stronger overall social skills.

White (2015) considered the teacher-child relationship in preschool and kindergarten to be related to the children's behavior and academic success in primary school. For instance, children who have good teacher-child relationships in preschool or kindergarten are more positive about primary school than children without such a relationship (White, 2015). Similarly, children who do not have good relationships with their teachers in early childhood display less interaction with their peers, express more disappointment, and show less tolerance of others, as compared to those with good relationships (White, 2015). Moreover, White showed that there is a connection between children's academic performance and their relationships with teachers: Children who had good relationships with early-childhood teachers later showed higher reading performance.

Teachers can provide many opportunities for children to interact during class. Wu et al. (2018) mentioned that developing children's social and emotional competence is essential to ensuring their readiness for school. Furthermore, teacher-child relationships are associated with many important aspects of life, including academic achievement, behavior, mental health, and physical health (Wu et al., 2018). Additionally, Wu et al. explained that early childhood is a critical period because, at this stage, children begin to practice emotional control and sometimes are able to take time to deal with their emotions.

Wu et al. (2018) mentioned that a warm and comfortable classroom climate with strong support from teachers is very effective at improving children's academic achievement; children in these environments show good behavior in class and interact well with others. Thus, healthy teacher-child relationships support children's development and have benefits that last until adulthood.

\subsection{Communication with Peers}

In the classroom, communication between peers is just as important as communication with teachers. Thus, learning-based collaboration and communication can help children to develop social and emotional skills. Moreover, teachers can help children to communicate with each other through the use of small-group and whole-group activities. Breeman et al. (2015) stated that children's interactions with their peers have a great impact on their social, emotional, and behavioral development.

\subsection{The Importance of the Teacher-Child Relationship}

The teacher-child relationship is important because it forms the foundation for many skills. Healthy teacher-child relationships in early childhood help to create healthy adolescents. Many researchers have found that the teacher-child relationship affects many aspects of children's development. For example, the teacher-child relationship supports the growth of social and emotional skills, as well as academic achievement and healthy behavior. For instance, Lippard et al. (2018) declared that children's classroom behavior is strongly linked to the teacher-child relationship.

Lippard et al. (2018) mentioned that the teacher-child relationship affects children's academic success. Lippard et al. (2018) also declared that positive teacher-child relationships support children's social, emotional, and cognitive development. Lippard et al. (2018) then confirmed that children's experiences with teachers are very important to their social and emotional development, academic achievement, and classroom behavior. White (2015) mentioned that a successful, smooth transition from kindergarten to first grade has a strong connection to previous teacher-child relationships.

\subsection{Building Teacher-Child Relationships}

There are many ways to build healthy teacher-child relationships. Various strategies and activities can encourage children to interact with their teachers and peers:

- Welcoming each child to class in the morning with a smile

- Giving each child a job and the time to complete it

- Using a calm voice

- Listening to children when they talk and asking them to listen to their peers 
- Giving children attention

- Using warm body language

- Asking distressed children about what is upsetting them

- Encouraging children to welcome each new day

- Using eye contact when talking to children

- Sitting at the children's level to provide good interactions

- Using simple words when talking with children

- Addressing the children by their names

- Applying one-on-one strategies to treat each child as an individual

- Engaging in small-group activities

- Asking children to participate in collaborative play

- Encouraging children to interact with others

Building a healthy teacher-child relationship is very significant for young children. For instance, Ng and Bull (2018) found that the use of daily classroom routines facilitated children's social and emotional learning.

Building a strong relationship with children starts on the first day of school; for instance, teachers can greet children with a smile, warmly welcome them, talk to them with a soft voice, and help them to have comfortable interactions. Ng and Bull (2018) found that the use of multiple strategies makes teaching more effective in terms of supporting children's social and emotional development.

Various strategies should be used to build a healthy teacher-child relationship; this is a simple way of helping young children.

In the following section, we provide more details about important aspects associated with children's social and emotional development and the teacher-child relationship. These social and emotional skills affect both academic achievement and behavioral skills.

\section{What Is Social-Emotional Learning?}

According to Durlak, Domitrovich, Weissberg, and Gullotta (2015), in their book Handbook of social and emotional learning: Research and practice, social-emotional learning is:

"Involves fostering social and emotional competencies through explicit instruction and through student-centered learning approaches that help students engage in the learning process and develop analytical, communication, and collaborative skills" (p. 6).

\subsection{Social-Emotional Learning and Academic Success}

Creating a productive and positive generation has never been easier than it is in today's educational system, thanks to improved social and emotional support. Homes are the first place where children grow and learn; the school setting comes afterward. The relationships between teachers and students can affect students' learning outcomes and personalities as well. Greater positivity in these relationships and in the school atmosphere helps children to be more productive, both academically and socially. In addition, healthy growth in all developmental domains has a long-lasting positive affect on their lives - especially their academic lives.

In several studies, researchers have proven that there are links between children's social and emotional development and their academic achievement. To ensure positive educational outcomes, researchers need to focus on fostering healthy growth in children's social and emotional skills. According to Nix, Bierman, Domitrovich, and Gill (2013), the development of children's social and emotional competence directly influences their engagement in learning and thus facilitates their current and future academic achievement. In addition, to ensure strong academic achievement and high test scores, more social and emotional support for students is needed (Nix et al., 2013).

Schools and teachers play a fundamental role in young children's lives. When children adapt well to school, this is often the result of their teachers' and peers' positive attitudes and relationships. The first people who children communicate with outside of their homes are often people at school (teachers, faculty members, and peers). Thus, young children often consider their teachers to be role models, and teachers have a huge effect on children's adaptation to the learning environment. Moreover, teachers can make children either love or hate school. A simple way to ensure productive and positive academic outcomes is to provide children with healthy social and emotional 
relationships. Nix et al. (2013) illustrated that children's language development, literacy skills, and learning engagement are associated with their social and emotional learning.

Nix et al. (2013) indicated that, when children engage in social and emotional learning, starting in preschool, this improves their future learning engagement, academic success, and readiness for school. Additionally, Morris, Millenky, Raver, and Jones (2013) said that, to facilitate children's completion of academic work, a positive social and emotional climate is required. Young children learn in parallel with their peers and teachers (Denham, Bassett, Thayer et al., 2012), so they employ their emotions to make learning easier.

According to Denham, Bassett, Thayer et al. (2012), many researchers have indicated that early-childhood social and emotional learning can promote children's cognitive development and enhance their classroom learning. Furthermore, social and emotional developmental skills are associated with children's failure or success in terms of sociability, school readiness, academic achievement, learning, and other challenges (Denham, Bassett, Thayer, et al., 2012). Successful transitions to schools' environments can set young children up for academic and social success; by contrast, failed transitions can leave children in a cycle of failure, both socially and academically (Denham, Bassett, Thayer et al., 2012). Denham, Bassett, Thayer, et al. emphasized the importance of establishing successful experiences in the early-school years to improve young children's attitudes, feelings, and adaptations with regard to learning. In addition, Denham, Bassett, Thayer, et al. said that, to ensure students' future academic success, they need to experience positive emotions and be socially involved at a young age.

Young children face difficulties in school adjustments when they have experienced poor social competence (Denham, Bassett, Thayer et al., 2012). Moreover, Denham, Bassett, Thayer et al. (2012) mentioned that children's capacity for emotional regulation affects their adjustment to school and their academic success. Denham, Bassett, Thayer, et al. also said that children who experience negative emotions are not always able to focus on learning but that children who experience positive emotions are more easily able to focus on learning. Hence, when children experience more positive relationships and interactions, they have stronger academic achievement, learning outcomes, and classroom-task engagement (Denham, Bassett, Thayer et al., 2012).

The regulation of preschoolers' emotions can predict their academic achievements through kindergarten and into the later school years (Denham, Bassett, Thayer et al., 2012). Social and emotional competence can also reinforce and even enhance academic success (Denham, Bassett, Thayer et al., 2012). Moreover, according to Ashdown and Bernard (2011), young children's well-being and school success are connected with their development of social and emotional skills. Early-childhood teachers help children start to learn about social and emotional competence (which is connected to their academic and social success). Ashdown and Bernard mentioned that early-childhood teachers foster children's social and emotional development because they know how to respond in a certain way. Ashdown and Bernard also indicated that learning social and emotional skills improves children's competence in reading and writing; critical thinking; learning motivation; and communication, interaction, and collaboration with peers and teachers.

Ashdown and Bernard (2011) identified several studies in which researchers have illustrated positive long-term effects of teaching students social and emotional skills in early childhood. A skilled early-childhood teacher should have warm verbal interactions with children to stimulate learning (Ashdown \& Bernard, 2011). Ashdown and Bernard emphasized the importance of social and emotional competence in young children's well-being, as well as their academic achievement in all learning domains.

We found connections between both social and emotional learning and children's performance in academic and social contexts. When young children feel happy, comfortable, loved, understood, and listened to, they are more likely to be ready for school and to perform well in their academic tasks than if they did not experience these feelings. Social and emotional competence plays a critical role in young children's school readiness and academic success; indeed, social and emotional skills are as important as any other learning skills.

Denham, Bassett, Mincic et al. (2012) indicated that many researchers now are focusing on social and emotional development, rather than just on cognitive development; social and emotional development affects well-being and academic success later in life. In addition, Denham, Bassett, Mincic et al. (2012) said that schools allow for widespread social interactions, which facilitate academic learning. To help children achieve social and emotional competence, teachers need to be skilled at applying classroom roles and directions to allow students to experience freedom (Denham, Bassett, Mincic et al., 2012). Furthermore, to engage effectively with classroom tasks and achieve high academic performance, students must have positive emotional regulation; negative emotions can cause low academic outcomes and can reduce classroom engagement (Denham, Bassett, Mincic et al., 2012).

Many researchers have argued about whether young children's social and emotional development have a long-term effect on their academic achievement and school success. According to Denham, Bassett, Mincic et al. (2012), 
many scholars have shown the benefits of beginning to practice behavioral regulation at an early age in terms of children's future academic success. According to Denham, Bassett, Mincic et al. (2012), these behavioral regulations include following directions, having input into the creation of classroom rules, engaging in complex activities, brainstorming questions, maintaining focus, completing challenging tasks, and asking for assistance when needed.

Collie, Martin, Nassar, and Roberts (2018) emphasized that, to be healthy (both inside and outside of school), children must have well-developed social and emotional competence. Collie et al. also demonstrated a positive connection between higher social and emotional competence and each of the following: higher academic outcomes, better school readiness, stronger educational engagement, higher rates of completing and continuing studies, and better well-being.

For instance, when considering the importance of social and emotional competence in young children, it is important to consider the Saudi Arabia's early-childhood program has only women teachers. According to the Saudi Ministry of Education of Early Childhood (2019), the main goal of the early-childhood levels is to prepare children to enter general education. Early-childhood education in Saudi Arabia is focused on developing children's well-being, giving them life skills, and ensuring that they are ready for future learning.

James (2010) illustrated that female teachers, as compared to male teachers, are more persistent, exhibit much more clemency with students, and are better able to adjust their teaching styles. In the future, the percentage of female teachers will rise, especially in the early-childhood field (James, 2010). In addition, James said that, because women are naturally more likely than men to take care of children at home, it is much easier for women to continue this work in the classroom setting.

\subsection{How Social and Emotional Development Affects Young Children's Behavior?}

It is very natural to observe young children in the classroom environment as they try to manage the numerous difficulties of their day-to-day lives. Few children find it very difficult to accommodate new friendships, and few exhibit undesirable classroom behaviors (Anliak \& Sahin, 2010). Still, Anliak and Sahin (2010) found that some young children express aggression, shyness, and/or withdrawal in the classroom structure. These children require support to overcome their difficulties before they grow older, when such behaviors become more challenging (Anliak \& Sahin, 2010). Children can showcase these difficult behaviors for many reasons; one of reasons that teachers have identified is that, as development and growth proceeds through the life span, children find it difficult to cope with these changes.

Another important aspect of acceptable behavioral skills arises from positive peer friendships in the early-childhood classroom. Young children who have good peer relationships tend to learn positive behaviors such as social competence, motivation, attention, and perseverance. On the other hand, young children with adverse peer relationships tend to experience lesser peer acceptance and to have various troublesome traits such as hyperactivity and inability to concentrate. Such children, relative to those with good peer relationships, have greater levels of aggression and much lower levels of social accommodation and academic achievement (Cohen \& Mendez, 2009).

Teacher-child relationships also play a vital role in strengthening positive young children's behavioral skills. Many researchers have noted that close child-teacher relationships serve a governing function for children who engage in problematic behavior-helping, for example, in these children's social interactions (Brock \& Curby, 2014). If the teacher-child relationship is not strong, the teacher cannot regulate the child's negative behavior, which could enhance the child's disconnection from social interactions (Brock \& Curby, 2014).

\section{Strategies to Foster Positive Social Skills}

As discussed earlier, due to the rapid development that takes place in early childhood, children often face social and emotional difficulties. Though most young children eventually overcome these developmental difficulties, in many cases, such difficulties are predictive of future developmental instability. Behavioral difficulties in young children are increasingly a major concern of early childhood professionals. Research and practical advancements in the development, testing, and implementation of methods for ensuring positive social and emotional development have reduced the frequency of negative behavioral problems in early childhood (Poulou, 2013).

In the following sections, we explore various research-proven strategies and best practices for enhancing behavioral skills through social and emotional development.

\subsection{Art-Based Approaches}

Children should be encouraged to use art (whether copying, drawing, painting, or sculpting) to interact. Such 
activities help children to develop new ways of working and interacting (Laroche, 2015). Freedman (2010) explained, "We must acknowledge benefits of a classroom learning community in which students interact, help, and push each other to improve their work" (p. 13). For example, in one of the classroom Laroche observed from this study, Joel (a well-behaved, academically advanced boy) drew and colored pictures with refinement and skill; he thus was one of the teacher's favorite students. Each month, the teacher rearranged the students' desks; in the month of the observation, Joel shared a desk with Vincent, who is very different from Joel due to an established pattern of imprudent behavior. Laroche observed, Vincent constantly fought with his peers and with the teacher, and he often spoke very rudely and out of turn. Laroche observed, Vincent also had difficulty sitting in one place and tended to roam the classroom because of a poor attention span. However, Laroche observed, when Vincent was sitting beside Joel and copying his drawings, Vincent worked very carefully and with extreme concentration. Laroche observed, even in subsequent months, when Vincent was no longer sitting next to Joel, he would sit next to Joel during art class. Laroche observed, Joel did complain to the teacher that Vincent was sitting beside him and copying his drawings. However, the teacher explained to Joel that Vincent liked Joel's drawings, which was why he copied them. The teacher also explained that this was an opportunity for them to work and learn together (Laroche, 2015). This example reveals that Vincent's behavioral skills improved due to his social interactions with Joel during the art class. In preschool, social competence is largely established and developed through such peer play. Cohen and Mendez (2009) stated that it is important for children's overall social and emotional well-being that they have healthy peer interactions. The preschool setting provides young children with many opportunities to interact with their peers and to develop positive behavioral skills (Cohen \& Mendez, 2009).

\subsection{The I Can Problem Solve Intervention}

Many impact-based interventions exist for training young children in social and problem-solving skills. These interventions also are meant to decrease negative behaviors and increase academic achievement. Effective interventions should enhance young children's problem-solving skills from a multidimensional perspective - including cognition, emotion, and behavior. One such multidimensional program, which is based on cognitive problem-solving skills, is called I Can Problem Solve; this program addresses behaviors such as impulsiveness, inability to wait, aggressiveness, and frustration while promoting positive prosocial behaviors (Anliak \& Sahin, 2010).

The training setting of the I Can Problem Solve (Shure, 2001) program is meant to help young children avoid problematic situations and to solve problems using cognitive skills (Anliak \& Sahin, 2010). This study's observations lasted 4 months and included 83 classes; the observed activities involved pictures, puppets, drama, and role playing. Each of the lessons in the intervention lasted 20 to $30 \mathrm{~min}$ (based on the children's interest levels). The results of this study demonstrate that a variety of programs can improve social competency, including social-skills trainings and behavioral programs that are meant to reduce aggressive behavior.

\subsection{Parent-Teacher Relationships}

The parent-teacher relationship supports the regulation of children's achievement and behavior prior to the start of formal schooling. Researchers have shown that children whose parents and teachers both report very good cooperation have better academic and social skills, as well as less extreme behavioral problems, as compared to those whose parents report lesser cooperation. In a Norwegian longitudinal study, the parents and teachers of $38 \%$ of the children in the sample reported having a very good cooperative relationship; $24 \%$ had strong cooperation only from the teachers' perspective, and another $17 \%$ had very good cooperation only from the parents' perspective; finally, in $20 \%$ of cases, neither the parents nor the teachers reported strong cooperation (Cook, Dearing, \& Zachrisson, 2018).

\subsection{Peer Relationships}

In this study, we examined the stability of preschoolers' peer-play behaviors across the school year so as to consider the relationships among emotional regulation, receptive vocabulary, and the trajectory of social-competence deficits. The sample comprised preschool students attending a Head Start program; the students were primarily African American and from families with low socioeconomic status. Their peer-play behavior was moderately stable from fall through spring. At the start of the study, we found that emotional difficulties were consistently associated with maladaptive behaviors and declining social competence. Furthermore, children who exhibited stable maladaptive behaviors had lower receptive-language skills and worse emotional regulation than did children who exhibited consistent adaptive behavior. The students who had comorbid externalizing and internalizing behaviors during peer play were at the greatest risk of having consistent difficulties or declining social competence over the course of the year, as compared to their peers. This study's results can inform future practices with regard to identifying at-risk preschoolers soon after they begin their early-childhood education 
experiences. Moreover, the findings suggest that, without effective interventions, such at-risk children are likely to exhibit consistently poor social competence over time. This study also has implications for the use of early interventions for targeting specific behavioral and peer-play problems (Cohen \& Mendez, 2009).

\subsection{Teacher-Child Relationships}

For young children, the teacher-child relationship supports their ability to improve behavioral skills. It is very challenging for teachers to support young children in terms of these behavioral skills, but teachers have a significant effect on young children; researchers have argued that close child-teacher relationships serve a central function for young children who have behavioral difficulties and set an example for these children's social collaborations (Brock \& Curby, 2014). Children who have bad relationships with their teachers have high levels of behavioral problems and low levels of competence (Pianta, 2004).

\section{Conclusion}

To sum up, social and emotional skills are related to communication skills and the ability to form connections with people, both inside and outside of school. Children need to learn various skills by interacting with their teachers and peers in order to develop their social and emotional competence. Social and emotional skills are fundamental, and the development of social and emotional competence leads to academic success and positive future learning. Moreover, young children with strong social and emotional skills can recognize and handle their behaviors in positive ways. The development of the social-emotional skills will lead to better school outcomes, adaption of future learning, well-being, and ability to manage good behaviors.

\section{References}

Anliak, S., \& Sahin, D. (2010). An observational study for evaluating the effects of interpersonal problem-solving skills training on behavioural dimensions. Early Child Development and Care, 180(8), 995-1003. https://doi.org/10.1080/03004430802670819

Ashdown, D. M., \& Bernard, M. E. (2012). Can explicit instruction in social and emotional learning skills benefit the social-emotional development, well-being, and academic achievement of young children? Early Childhood Education Journal, 39(6), 397-405. https://doi.org/10.1007/s10643-011-0481-x

Breeman, L. D., Wubbels, T., Van Lier, P. A. C., Verhulst, F. C., Van der Ende, J., Maras, A., \& Tick, N. T. (2015). Teacher characteristics, social classroom relationships, and children's social, emotional, and behavioral classroom adjustment in special education. Journal of school psychology, 53(1), 87-103. https://doi.org/10.1016/j.jsp.2014.11.005

Brock, L. L., \& Curby, T. W. (2014). Emotional support consistency and teacher-child relationships forecast social competence and problem behaviors in prekindergarten and kindergarten. Early Education and Development, 25(5), 661-680. https://doi.org/10.1080/10409289.2014.866020

Cadima, J., Verschueren, K., Leal, T., \& Guedes, C. (2016). Classroom interactions, dyadic teacher-child relationships, and self-regulation in socially disadvantaged young children. Journal of Abnormal Child Psychology, 44(1), 7-17. https://doi.org/10.1007/s10802-015-0060-5

Cohen, J. S., \& Mendez, J. L. (2009). Emotion regulation, language ability, and the stability of preschool children's peer play behavior. Early Education and Development, 20(6), 1016-1037. https://doi.org/10.1080/10409280903305716

Collie, R. J., Martin, A. J., Nassar, N., \& Roberts, C. L. (2019). Social and emotional behavioral profiles in kindergarten: A population-based latent profile analysis of links to socio-educational characteristics and later achievement. Journal of Educational Psychology, 111(1), 170-187. https://doi.org/10.1037/edu0000262

Denham, S. A., Bassett, H. H., Thayer, S. K., Mincic, M. S., Sirotkin, Y. S., \& Zinsser, K. (2012). Observing Preschoolers' Social-Emotional Behavior: Structure, Foundations, and Prediction of Early School Success. Journal of Genetic Psychology, 173(3), 246. https://doi.org/10.1080/00221325.2011.597457

Denham, S. A., Bassett, H., Mincic, M., Kalb, S., Way, E., Wyatt, T., \& Segal, Y. (2012). Social-emotional learning profiles of preschoolers' early school success: A person-centered approach. Learning and individual differences, 22(2), 178-189. https://doi.org/10.1016/j.lindif.2011.05.001

Durlak, J. A. (Ed.). (2015). Handbook of social and emotional learning: Research and practice. Guilford Publications.

Graves Jr., S. L., \& Howes, C. (2011). Ethnic differences in social-emotional development in preschool: The 
impact of teacher child relationships and classroom quality. School Psychology Quarterly, 26(3), 202-214. https://doi.org/10.1037/a0024117

James, J. H. (2010). Teachers as mothers in the elementary classroom: Negotiating the needs of self and other. Gender and Education, 22(5), 521-534. https://doi.org/10.1080/09540250903519436

Laroche, G. A. (2015). Social learning and drawing: What children learn by copying the images of their peers. Art Education, 68(3), 19-25. https://doi.org/10.1080/00043125.2015.11519318

Lippard, C. N., La Paro, K. M., Rouse, H. L., \& Crosby, D. A. (2018). A closer look at teacher-child relationships and classroom emotional context in preschool. Child \& Youth Care Forum, 47(1), 1-21. https://doi.org/10.1007/s10566-017-9414-1

Morris, P., Millenky, M., Raver, C. C., \& Jones, S. M. (2013). Does a preschool social and emotional learning intervention pay off for classroom instruction and children's behavior and academic skills? Evidence from the foundations of learning project. Early Education \& Development, 24(7), 1020-1042. https://doi.org/10.1080/10409289.2013.825187

Ng, S. C., \& Bull, R. (2018). Facilitating Social Emotional Learning in Kindergarten Classrooms: Situational Factors and Teachers' Strategies. International Journal of Early Childhood, 50(3), 335-352. https://doi.org/10.1007/s13158-018-0225-9

Nix, R. L., Bierman, K. L., Domitrovich, C. E., \& Gill, S. (2013). Promoting children's social-emotional skills in preschool can enhance academic and behavioral functioning in kindergarten: Findings from Head Start REDI. Early Education \& Development, 24(7), 1000-1019. https://doi.org/10.1080/10409289.2013.825565

Pianta, R. C., \& Stuhlman, M. W. (2004). Teacher-child relationships and children's success in the first years of school. School psychology review, 33(3), 444.

Poulou, M. S. (2015). Emotional and behavioural difficulties in preschool. Journal of Child and Family Studies, 24(2), 225-236. https://doi.org/10.1007/s10826-013-9828-9

Sutherland, K. S., Conroy, M. A., Algina, J., Ladwig, C., Jessee, G., \& Gyure, M. (2018). Reducing child problem behaviors and improving teacher-child interactions and relationships: A randomized controlled trial of BEST in CLASS. Early Childhood Research Quarterly, 42, 31-43. https://doi.org/10.1016/j.ecresq.2017.08.001

White, K. M. (2015). "My Teacher Helps Me": Assessing Teacher-Child Relationships from the Child's Perspective. Journal of Research in Childhood Education, 30(1), 29-41. https://doi.org/10.1080/02568543.2015.1105333

Wu, Z., Hu, B. Y., Fan, X., Zhang, X., \& Zhang, J. (2018). The associations between social skills and teacher-child relationships: A longitudinal study among Chinese preschool children. Children and Youth Services Review, 88, 582-590. https://doi.org/10.1016/j.childyouth.2018.03.052

\section{Copyrights}

Copyright for this article is retained by the author(s), with first publication rights granted to the journal.

This is an open-access article distributed under the terms and conditions of the Creative Commons Attribution license (http://creativecommons.org/licenses/by/4.0/). 